\title{
Development of a Commercial Process for the Production of Silicon Carbide Fibrils
}

\section{Draft Phase II Final Report}

\author{
Prepared By \\ Richard D. Nixdorf \\ ReMaxCo Technologies, Inc. \\ 1010 Commerce Park Drive, Suite I \\ Oak Ridge, Tennessee 37830 \\ Tele: $865-482-7552$ \\ Fax: 865-482-7505 \\ Email: nixdorfr@indceramicsolns.com
}

October 2002

Under

Subcontract No. X-SZ337V

For

Oak Ridge National Laboratory

Oak Ridge, Tennessee 37831

Managed By

UT-Battelle LLC 


\section{TABLE OF CONTENTS}

\section{$\underline{\text { Page }}$}

Table of Contents 1

1 Abstract 3

2 Introduction 4

3 Technical Approach 5

$\begin{array}{lll} & \text { Experimental Procedure } & 7\end{array}$

5 Results 9

6 Conclusions 12

$\begin{array}{lll}7 & \text { Future Work } & 12\end{array}$

$\begin{array}{ll}\text { References } & 13\end{array}$

\section{Figures}

1 Microwave reactor schematic

2 Semi-continuous microwave reactor in operation

3 Thermodynamic analysis of process

$4 \quad$ Metal MTS bubbler

$5 \quad$ Glass MTS bubbler

$6 \quad$ Ceramic boat with Fibrils product

$7 \quad$ Microwave zone during fibril growth

8 Digital photo of Fibrils in boat

9 Electron microscopy of Fibril product

10 Electron microscopy showing single crystal 
11 Fibril growth ball showing VLS growth

12 Electron microscopy of SP4000 Fibril product

$132000 X$ of SP4000 Fibril

14 Melt balls showing VLS growth with SP4000

15 Large Fibril from melt ball 


\section{Abstract}

The current work continues a project completed in 1999 by ReMaxCo Technologies in which a novel, microwave based, VLS Silicon Carbide Fibrils concept was verified. This project continues the process development tof a pilot scale commercial reactor. Success will lead to sufficient quantities of fibrils to expand work by ORNL and others on heat exchanger tube development. A semicontinuous, microwave heated, vacuum reactor was designed, fabricated and tested in these experiments. Cylindrical aluminum oxide reaction boats are coated, on the inner surface, with a catalyst and placed into the reactor under a light vacuum. A series of reaction boats are then moved, one at a time, through the reactor. Each boat is first preheated with resistance heaters to $850^{\circ} \mathrm{C}$ to $900^{\circ}$ $\mathrm{C}$. Each reaction boat is then moved, in turn, to the microwave heated section. The catalyst is heated to the required temperature of $1200^{\circ} \mathrm{C}$ to $1300^{\circ} \mathrm{C}$ while a mixture of MTS (methyl trichlorosilane) and hydrogen are introduced into the annulus of the boat. The MTS is dissociated to allow the carbon and silicon components to be dissolved into the catalyst. The catalyst saturates and precipitates silicon carbide onto the surface of the reaction boat to grow the Fibrils. The reaction continues as long as the MTS is introduced into the reactor.

The major obstacle that had to be overcome during this project was the performance of the reactor. The original design of the reactor focused the microwaves in such a manner that they missed the catalyst/Fibrils growth zone. The microwaves did react with the insulation and the reactor was heated by heating the insulation. Modifications were made to the reactor to focus the microwaves on the catalyst. SiC Fibrils were produced using both MTS and Starfire SP4000 as feed-gas precursors. Both precursors produced fibrils at temperatures of less than $1000^{\circ} \mathrm{C}$. The new Starfire SP4000 produced fibrils as low as $800^{\circ} \mathrm{C}$, without the use of hydrogen and without producing the hazardous hydrochloric acid. Experimental results and scanning electron microscopy of the Fibril products are presented. Future work to improve on these results is discussed. 


\section{Introduction}

The U.S. Department of Energy desires to use Silicon Carbide Fibrils as reinforcement for fiber reinforced silicon carbide matrix composite heat exchanger tubes that would be fabricated by chemical vapor infiltration. The VLS silicon carbide fibrils are grown when gaseous reactants are dissolved into a liquid catalyst and precipitated on to the growing fibril. ReMaxCo Technologies began this project by manufacturing aluminum oxide fiber paper as a substitute for the silicon carbide fibrils for chemical vapor infiltration development work at Oak Ridge National Laboratory. When SiC fibril development work produces adequate quantities, silicon carbide fibril paper will replace the aluminum oxide fiber paper in the CVI heat-exchanger tube development process.

The major limitations of the current "state of the art" fibril growth are the high temperatures required $\left(1600^{\circ} \mathrm{C}\right.$ to $\left.1700^{\circ} \mathrm{C}\right)$, the slow fibril growth rate $(\sim 0.17$ $\mathrm{mm} / \mathrm{hr}$ ), and the large quantity of excess of expensive methyl trichlorosilane gas, which is wasted ${ }^{1}$. The commercial process is complicated by the processing of large quantities of hydrogen gas at high temperatures and the generation of corrosive hydrochloric $\mathrm{acid}^{2}$. This current work continues a proof-of-concept, microwave based, VLS process development completed in 1999 by ReMaxCo. The catalyst was heated to the experimental temperature $\left(1200^{\circ} \mathrm{C}\right.$ to $\left.1300^{\circ} \mathrm{C}\right)$ while a mixture of MTS and hydrogen were introduced into an aluminum oxide boat. The MTS is dissociated and the carbon and silicon components are dissolved into the catalyst. The catalyst saturates and precipitates silicon carbide onto the surface of the reaction boat. These experiments yielded fibril growth rates of $0.75 \mathrm{~mm} / \mathrm{hr}$. That was an improvement of approximately 4.4 times faster than the best graphite furnace runs ${ }^{3}$. It was also demonstrated that some volume of fibrils could be produced on the surface of the aluminum oxide boats.

This project continues the commercial process development to a pilot scale commercial reactor that will lead to sufficient quantities of fibrils to allow expanded work by Oak Ridge National Laboratory and others on heat exchanger tube development. A semi-continuous, microwave heated, vacuum reactor was designed, fabricated and tested in these experiments. The major obstacle that had to be overcome during this project was the performance of the reactor. The original design of the reactor focused the microwaves in such a manner that they missed the catalyst/fibrils growth zone. The microwaves did react with the insulation and the reactor was heated by coupling with the insulation. Modifications were made to the reactor to focus the microwaves on the catalyst. SiC Fibrils were produced using both MTS and Starfire SP4000 as feed-gas precursors. Both precursors produced fibrils at temperatures of less than $1000^{\circ} \mathrm{C}$. The new Starfire SP 4000 produced fibrils as low as $800^{\circ} \mathrm{C}$, without the use of hydrogen and without producing the hazardous hydrochloric acid. 


\section{Technology Approach}

A semi-continuous, microwave heated, vacuum reactor was designed, fabricated and tested to conduct all of the experiments for this project. The furnace is shown in Figures 1 and 2.

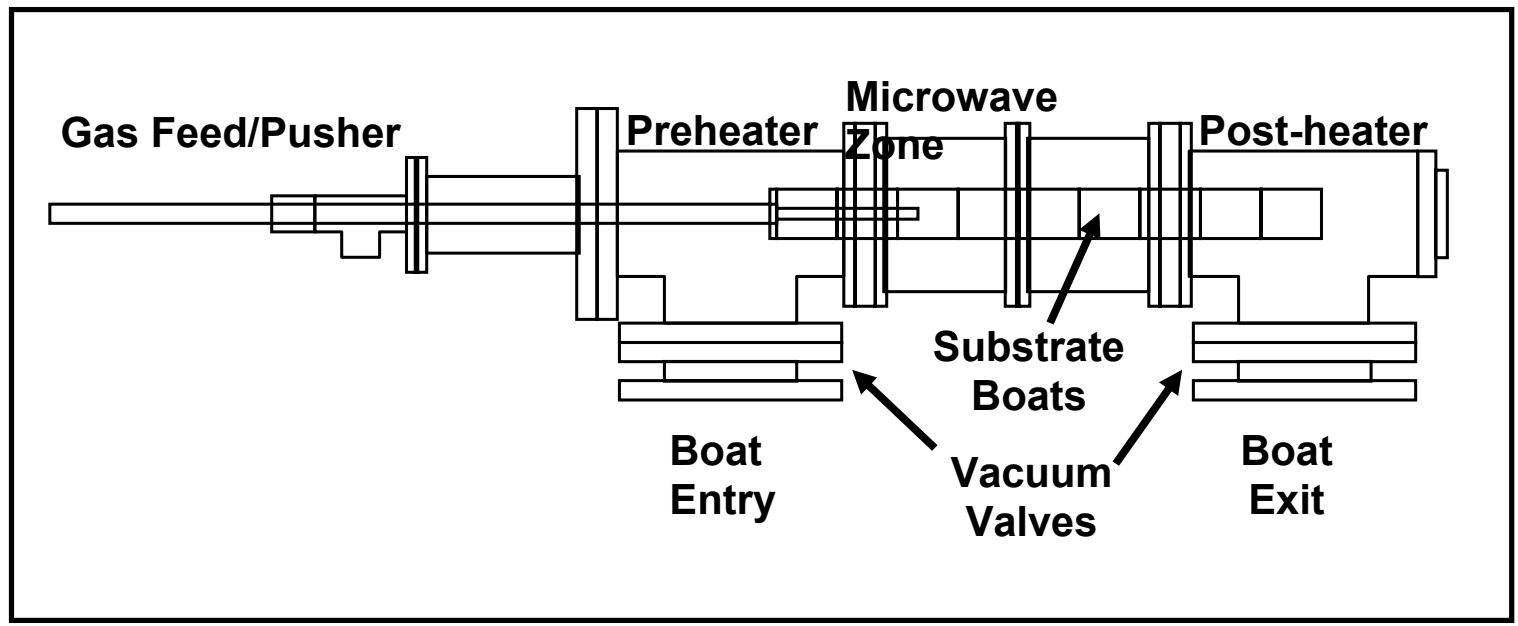

Figure 1. Schematic of Fibril microwave reactor

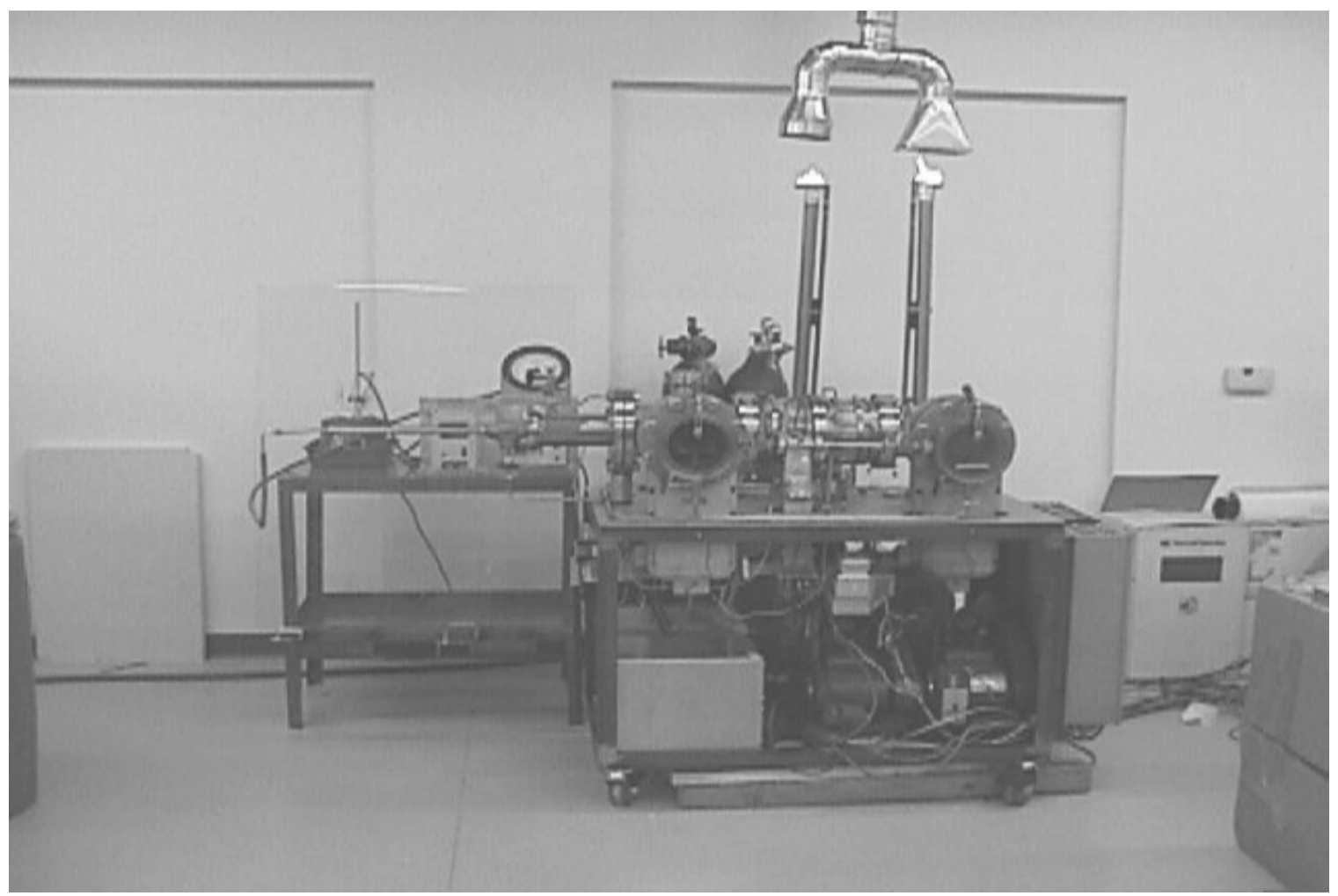

Figure 2. Fibril microwave reactor in operation 
The boundary conditions for the experiments were determined by running a computer thermodynamic analysis on the raw materials system. The results are shown in Figure 3.

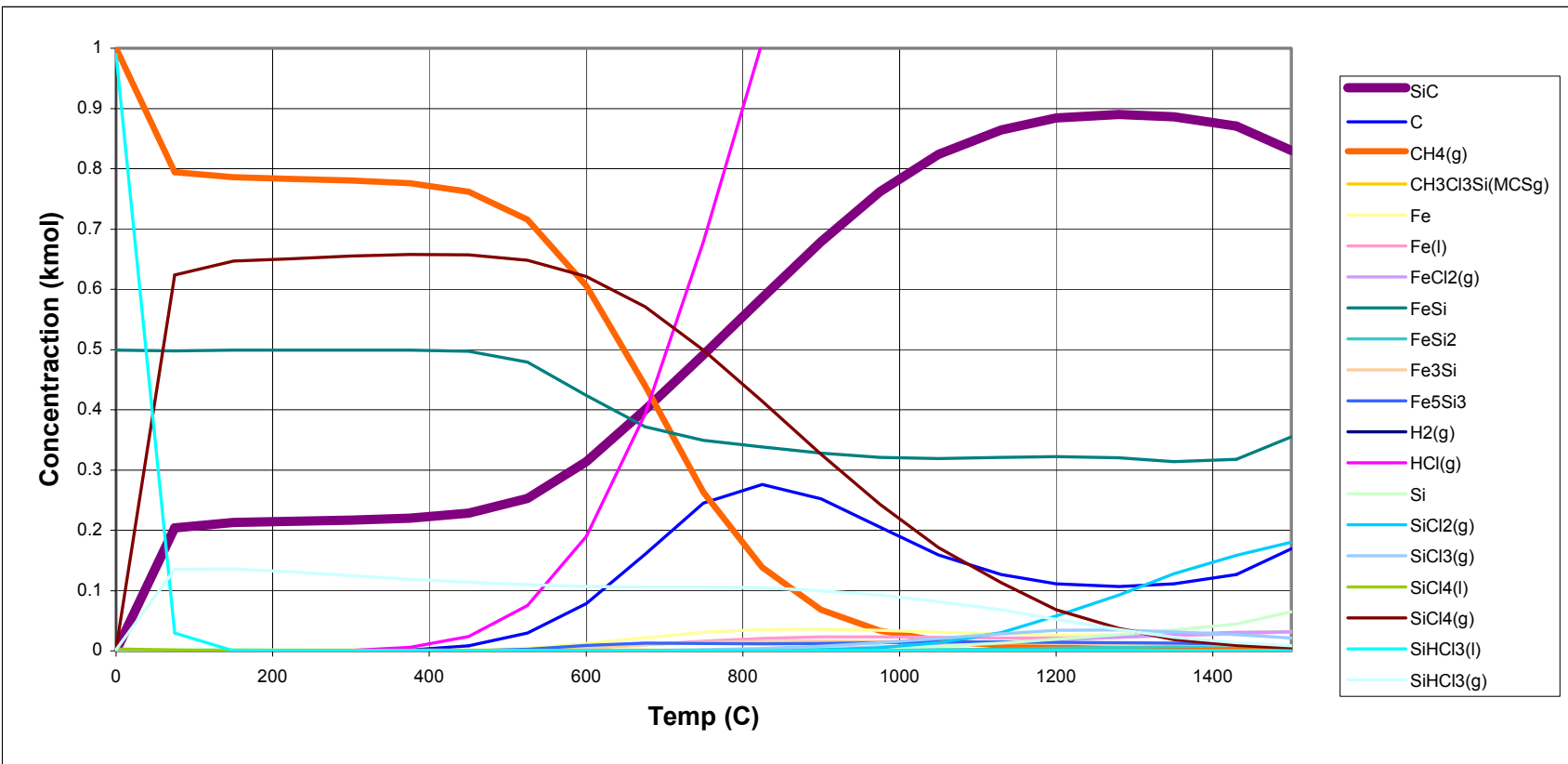

Figure 3. Thermodynamic analysis showing optimum temperature range for growing silicon carbide fibrils

Cylindrical aluminum oxide reaction boats were coated, on the inner surface, with a catalyst and placed into the reactor under a light vacuum. Several catalyst options were tested including ferrous silicon, iron powder and several mixtures thereof. A series of reaction boats traveled, one at a time, through the reactor. Each boat is first preheated with resistance heaters to $850^{\circ} \mathrm{C}$ to $900^{\circ} \mathrm{C}$. Each reaction boat was then moved, in turn, to the microwave heated section. The catalyst is heated to the required temperature of $1200^{\circ} \mathrm{C}$ to $1300^{\circ} \mathrm{C}$ while a mixture of MTS (methyl trichlorosilane) and hydrogen were introduced into the catalyst-coated area of the boat. The MTS forms the carbon and silicon components which dissolve into the catalyst to grow the Fibrils.

Once the furnace was debugged and running consistently, process optimization experiments were conducted to achieve fibril growth and define operating parameters. Fibrils from the final runs were submitted to Oak Ridge National Laboratory for analysis. The operating results from these experiments were used to design a second-generation microwave reactor to solve the problems that became apparent in operating the current reactor. There was also a group of 
experiments to identify a less hazardous raw material gas than the methyl trichlorosilane.

\section{$4 \quad$ Experimental Procedures}

\section{Experimental Microwave Reactor Operating Procedure}

1. Coat the inside annulus of reaction boats with $\mathrm{FeSi} 2$ catalyst paint

2. Dry the catalyst paint completely

3. Place reaction boat into the entry vacuum purge chamber

4. Vacuum purge and open the inner door

5. Push the new reaction boat into position, which indexes all the boats in the microwave zone forward

6. Preheat reaction boats with a resistance heater to $8000 \mathrm{C}$

7. Move the boats into the microwave-heated zone

8. MTS and hydrogen are injected into the boat

9. The microwave-heated catalyst causes the MTS to dissociate

10. The $\mathrm{C}$ and $\mathrm{Si}$ dissolve into the catalyst to initiate $\mathrm{SiC}$ Fibril growth

11. Continue until the desired fibril length is reached

12. Push the boat into the cooling section

13. Purged the exit chamber and withdraw the product boat

A number of runs were made to debug the microwave reactor and the reaction gas feed system. The MTS reaction gas is generated by bubbling hydrogen through liquid MTS in a steel container. The steel container was replaced with a transparent, heated glass bubbler to allow the operator to view the hydrogen flow through MTS liquid and control the vapor pressure of the MTS gas (Figures 4 and 5).

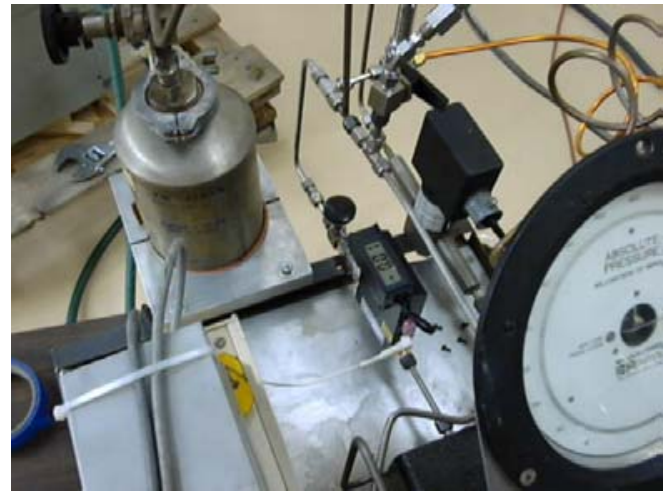

Figure 4. Metal bubbler

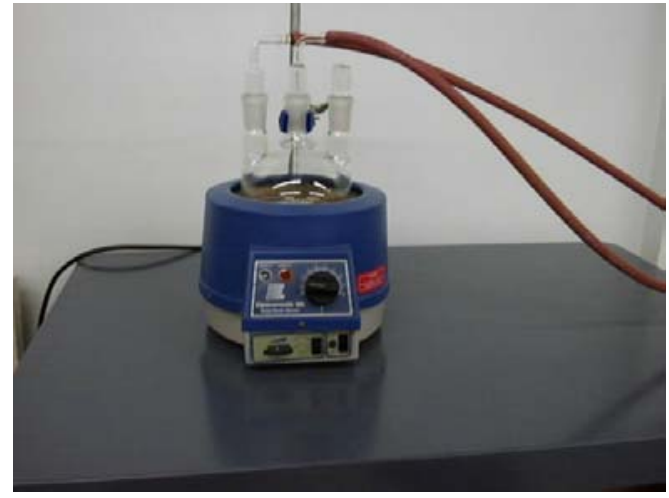

Figure 5. Glass bubbler 


\section{Silicon Carbide Fibrils Reaction Vessel Runs}

The fibril catalyst seed paint was prepared using metallurgical grade -325 mesh ferrous silicon mixed in a dispersant paint purchased from YZP Corporation in a $1: 1$ ratio. The paint was applied in a 0.1 -millimeter thick coating to the interior diameter of a 7.6 centimeter diameter $\times 7.6$ centimeter long high-density aluminum oxide cylinder. When the paint dried, the boats were loaded in the vacuum chamber of the microwave reactor. A boat that exhibits some Fibril growth is shown in Figure 6.

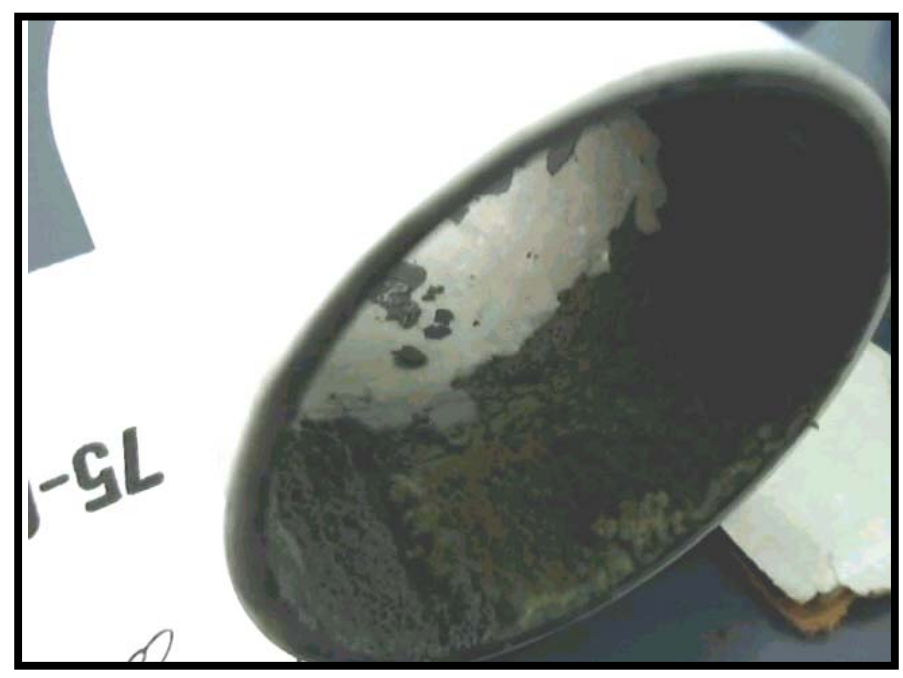

Figure 6. Ceramic boat with microwave grown Fibrils

The microwave reactor was evacuated by vacuum pumps to approximately 30 mTorr, and then flushed with nitrogen gas at a pressure of 150 Torr. After the nitrogen flush, the furnace was backfilled with hydrogen gas to a pressure of 150 Torr and maintained at less than 180 Torr throughout the microwave fibril growth run. The preheat zone resistance heaters were stabilized at $800^{\circ} \mathrm{C}$ and held there throughout the run. Each one of the two 2-KW microwave sources was stabilized at 1.8-KW. Hydrogen flow was run through the MTS bubbler at a rate of 0.13 liters/minute for a period of one to three hours. Figure 7 shows the reaction zone during microwave assisted silicon carbide fibril growth.

Figure 7. Fibril growth in the microwave field. Glowing annulus is the catalyst layer reacting to the microwave energy

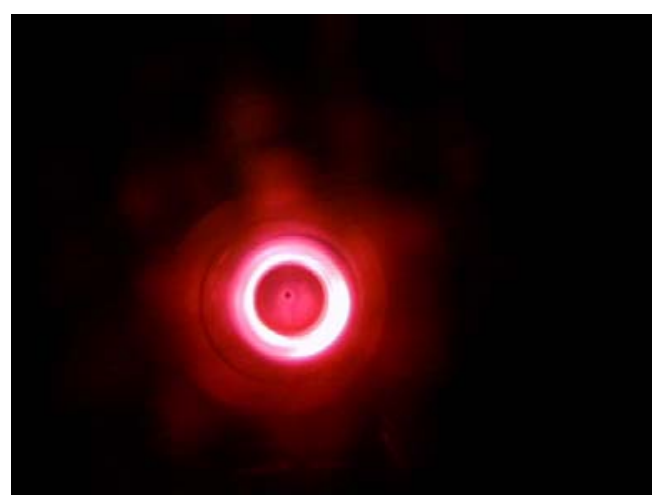


Additional optimization testing was conducted replacing ferrous silicon with iron particles, then a mixture of $50 \%$ ferrous silicon and $50 \%$ iron by weight. In addition, the procedure described above was tested replacing the MTS liquid with a SP4000, a polysilymethylene CVD silicon carbide precursor produced by Starfire Systems. The SP4000 can be reacted in nitrogen gas rather than the more dangerous hydrogen required by the MTS liquid and gas.

Typical Run Sheet:

$5 / 8 / 02$

\begin{tabular}{|l|l|}
\hline Reactant Gas & SP4000 \\
\hline Atmosphere & Hydrogen \\
\hline Catalyst & Fe \\
\hline Fibrils Observed & Yes \\
\hline
\end{tabular}

A nitrogen purge was used during start up.

14:45 Hydrogen was turned on

\begin{tabular}{|c|c|c|c|c|c|c|c|c|}
\hline Time & $\begin{array}{l}\text { MZ1 } \\
\text { (kW) }\end{array}$ & $\begin{array}{l}\text { MZ2 } \\
\text { (kW) }\end{array}$ & $\begin{array}{l}\text { GZ1 } \\
\text { (C) }\end{array}$ & $\begin{array}{l}\text { GZ2 } \\
\text { (C) }\end{array}$ & $\begin{array}{l}\text { Press } \\
\text { (Torr) }\end{array}$ & $\begin{array}{l}\text { Main } \\
\text { Flow } \\
\text { (lpm) }\end{array}$ & \begin{tabular}{|l} 
Bubbl \\
er \\
Flow \\
(lpm)
\end{tabular} & $\begin{array}{l}\text { Temp } \\
\text { (C) }\end{array}$ \\
\hline 15:00 & 1.80 & 1.80 & 530 & 484 & 175 & 0.52 & 0.08 & NR \\
\hline $15: 04$ & \multicolumn{8}{|c|}{ Some glow appeared in spots } \\
\hline 15:07 & \multicolumn{8}{|c|}{ MZ1 and MZ2 power adjusted to prevent arcing. GZ set pts to } \\
\hline $15: 18$ & \multicolumn{8}{|c|}{ GZ set points to $700 \mathrm{C}$} \\
\hline $15: 20$ & \multicolumn{8}{|c|}{ GZ set points to $800 \mathrm{C}$} \\
\hline $15: 30$ & 1.80 & 1.80 & NR & NR & NR & 0.52 & 0.13 & NR \\
\hline $16: 30$ & 1.90 & 1.90 & 801 & 734 & 165 & 0.52 & 0.13 & 854 \\
\hline $16: 45$ & 2.00 & 2.00 & 801 & 735 & 160 & 0.52 & 0.13 & 904 \\
\hline $17: 00$ & 2.00 & 2.00 & 802 & 738 & 185 & 0.51 & 0.13 & 909 \\
\hline $17: 40$ & 2.00 & 2.00 & 802 & 744 & 175 & 0.51 & 0.13 & 922 \\
\hline $17: 50$ & 2.00 & 2.00 & 800 & 742 & 180 & 0.51 & 0.13 & 921 \\
\hline $18: 00$ & 2.00 & 2.00 & 800 & 745 & 160 & 0.51 & 0.13 & 924 \\
\hline $18: 10$ & 2.00 & 2.00 & 800 & 745 & 170 & 0.51 & 0.13 & 924 \\
\hline $18: 30$ & 2.00 & 2.00 & 800 & 743 & 175 & 0.51 & 0.13 & 920 \\
\hline 19:00 & 2.00 & 2.00 & 800 & 745 & 165 & 0.51 & 0.12 & 921 \\
\hline
\end{tabular}

\section{$5 \quad$ Results}

The only fibril growth in the initial microwave field configuration happened after being in the microwave growth chamber for approximately three hours. The 
microwave intensity was measured in the fibril growth area and found to be zero. The furnace was rebuilt to focus more of the microwave field in the fibril growth zone. This improved the fibril growth quality and time. The fibrils grown in this sequence are shown in Figures 8, 9, 10, and 11. The fibril quality is good, but the fibril yield was very low. They are 2 to 5 micrometers in size.

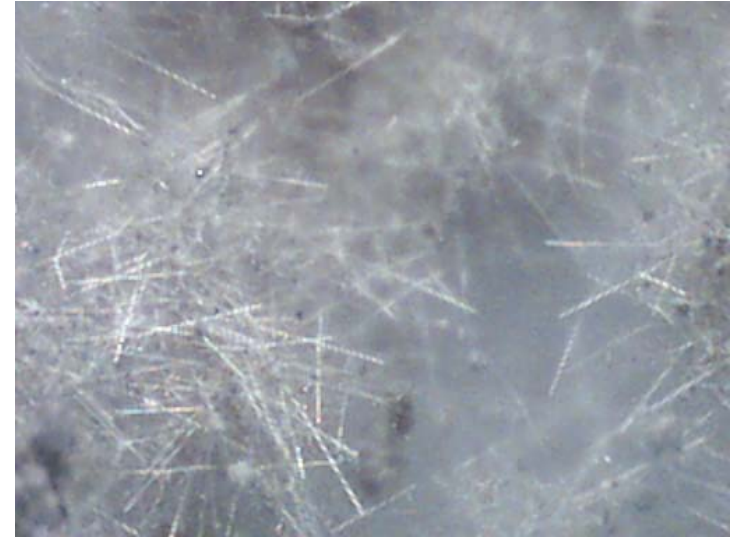

Figure 8. Fibril growth on the boat by digital camera

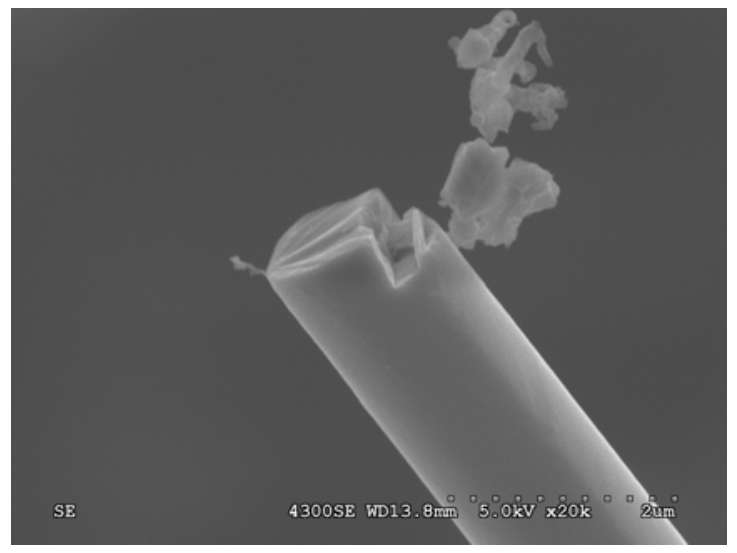

Figure 10. Electron microscopy shows perfect single crystal growth

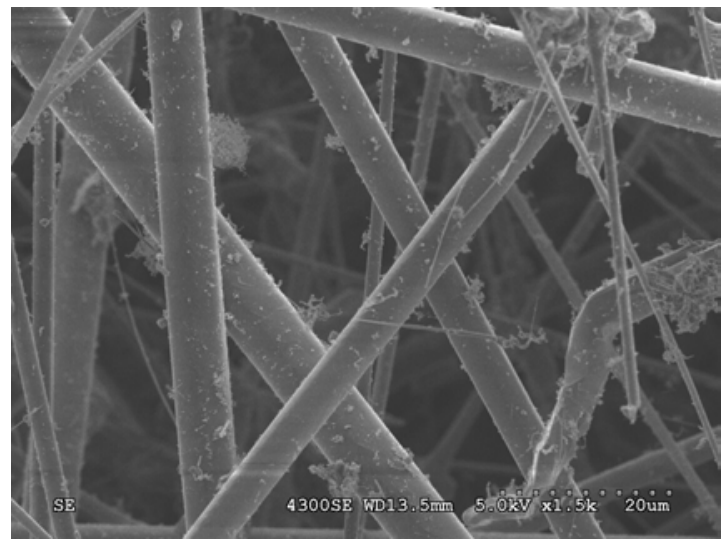

Figure 9. Electron microscopy of same Fibril product

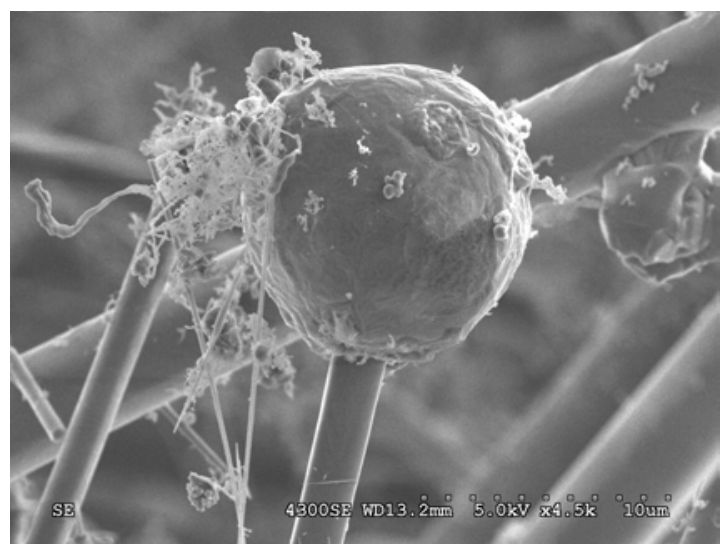

Figure 11. Fibril growth balls indicate true VLS growth process

There are a number of issues with the fibril reactor that need to be improved and will be implemented in the next phase of this work. The microwave field uniformity was poor and can be significantly improved. The catalyst paint tended to flake off the tops and sides of the round ceramic boats. Flat ceramic plates will be more efficient. Finally, the MTS gas feed mechanism had very little mass flow control and an irregular feed pattern to the fibril growth zone. A more accurate 
mass flow controller and a manifold-mixer are needed for the reaction gas distribution.

One of the problems with scaling the fibril development to a large-scale commercial process is the generation of significant quantities of hydrochloric acid in the off-gas stream. This acid destroys the vacuum system and the exhaust ducts. Silicon carbide fibrils were produced using the SP4000 in nitrogen. An unexpected advantage, beyond no acid in the off-gas, was the fact that fibrils grew at $850^{\circ} \mathrm{C}$. The MTS reaction required a temperature of $1200^{\circ} \mathrm{C}$ to $1300^{\circ} \mathrm{C}$. Fibrils grown in the SP4000 experiments are shown in Figures 12, 13, 14 and 15. They are 5 to 15 micrometers in diameter. Melt growth balls in Figure 14 were observed with the fibrils indicating that they were VLS.

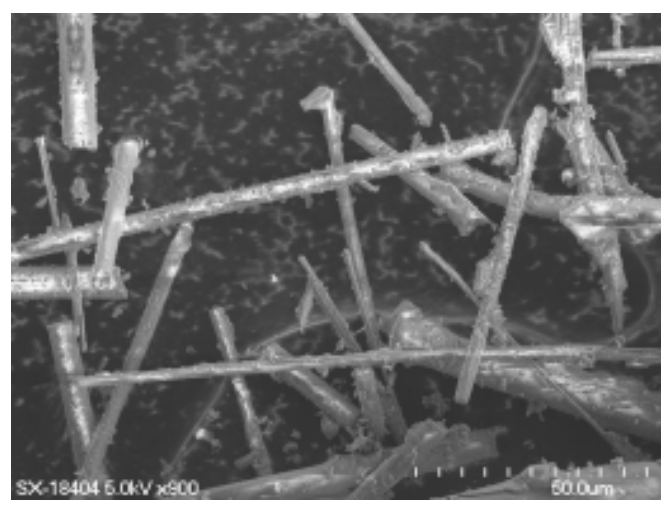

Figure 12. Scanning electron microscopy of SP4000 Fibrils

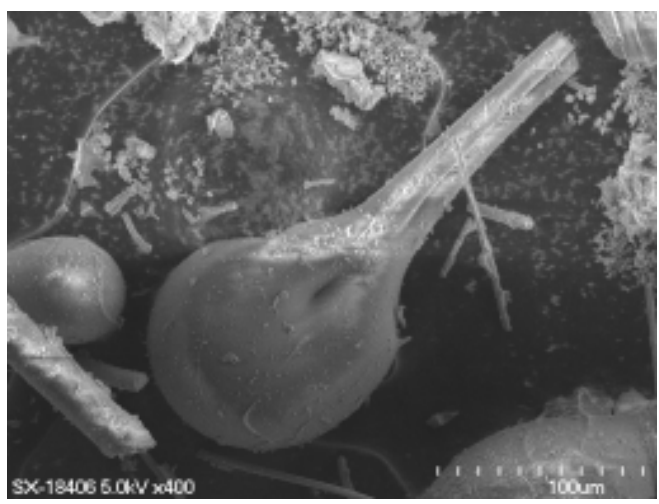

Figure 14. Melt growth balls indicating vapor-liquid-solid

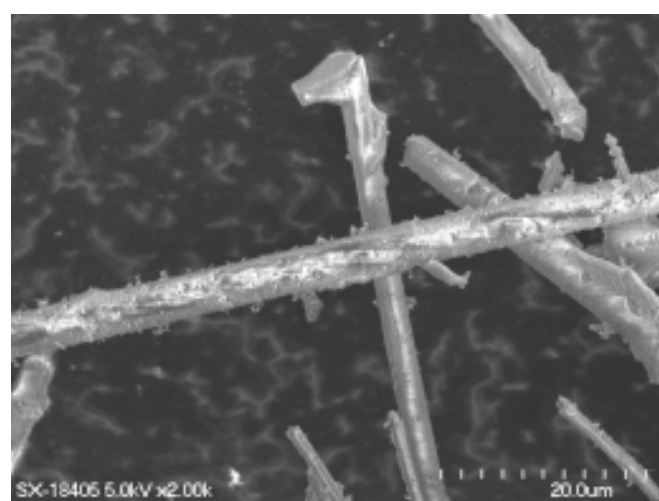

Figure 13. 2,000X magnification showing Fibril size

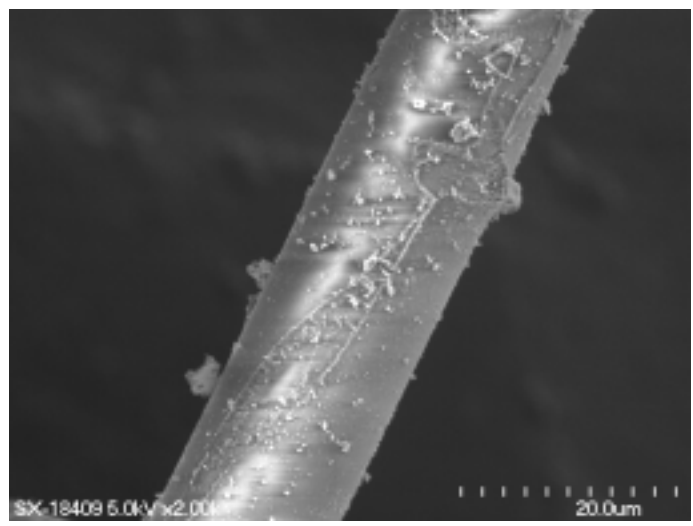

Figure 15. Fibril from growth ball 


\section{Conclusions}

These experiments demonstrated that silicon carbide fibrils could be produced at temperatures as low as $850^{\circ} \mathrm{C}$, as compared to the $1700^{\circ} \mathrm{C}$ in the previous graphite furnaces. The fibril growth rate has been increased by a factor of four over previous technologies. The microwaves are definitely playing a major role in improving the fibril growth process. The SP4000 silicon carbide precursor provides a reaction without hazardous off-gas products.

A commercial process is feasible by overcoming the equipment engineering problems encountered on this project. Those include a uniform microwave field, good control and uniform distribution of reactant gases, and the use of flat ceramic reaction boats. These improvements will get the commercial process closer to the $\$ 300$ per pound project goal.

With these improvements in place, one can improve on previous technology to accomplish:

1 Lower energy consumption

2 Higher growth rates

3 Reduced reactant gas waste

$4 \quad$ Lower cost raw materials

$5 \quad$ Consistent quality fibrils product

\section{$7 \quad$ Future Work}

A new pilot-scale reactor will be designed and fabricated, incorporating all of the improvements described above. That reactor will be tested, and then operated to supply sample quantities to various researchers in the Fossil Energy Materials Program. A small-scale production reactor will be designed. If a commercial application evolves, the reactor will be built.

\section{Acknowledgements}

The author acknowledges the support of the U.S. Department of Energy's (DOE) Fossil Energy through the Advanced Research Materials Program under the project direction of Dr. Roddie R. Judkins for the funding of this work. Gratitude is expressed to Oak Ridge National Laboratory's High Temperature Materials Laboratory for the electron microscopy work of Larry Allard and Larry Walker and to Microwave Materials Technology for microwave equipment engineering and fabrication. 


\section{References}

1. P.D. Shalek, et all, "Scale-Up and Optimization of the VLS Growth Process for Beta-SiC Whiskers for the Period of April 1982 September 1989", DARPA Final Report, DOE/OAR\&TD Topical Report, LA-12119, November 1991.

2. R.W. Ohnsorg, W.E. Hollar, Jr., and S.K. Lau, "Engineering Scale Development of Vapor-Liquid-Solid (VLS) Process for the Production of Silicon Carbide Fibrils" Phase II Report, ORNL/Sub/90-SD861/02, April 1995.

3. R.D. Nixdorf, "Development of a Commercial Process for the Production of Silicon Carbide Fibrils", Phase I Final Report, ORNL/Sub/98-SU604/01, April 1999. 